\title{
Criptococose: consequência da infecção por Cryptococcus neoformans em pacientes com AIDS no Brasil
}

\author{
Cryptococcosis: a consequence of Cryptococcus neoformans infection in AIDS patients in Brazil
}

Criptococosis: una consecuencia de la infección por Cryptococcus neoformans en pacientes con

SIDA en Brasil

Recebido: 31/10/2021 | Revisado: 07/11/2021 | Aceito: 13/11/2021 | Publicado: 16/11/2021

Eliete Fernandes Dos Santos

ORCID: https://orcid.org/0000-0002-8938-3807 Universidade Nilton Lins, Brasil

E-mail: elietefernandesly@gmail.com

Erick Frota Gomes Figueiredo

ORCID: https://orcid.org/0000-0002-6127-0544 Universidade Nilton Lins, Brasil

E-mail: erick.figueiredo@uniniltonlins.edu.br

\begin{abstract}
Resumo
Essa pesquisa possui como objetivo compreender as consequências da infecção por Cryptococcus neoformans em pacientes com AIDS no Brasil, assim como compreender o desenvolvimento do C. neoformans em pessoas com AIDS e destacar o diagnóstico, sintomas e a forma de tratamento da criptococose. O presente estudo consiste em uma pesquisa bibliográfica do tipo integrativa tendo como principais fontes: artigos, teses, revistas científicas e revistas eletrônicas. A plataforma digital busca forma: Scientific Eletronic Library Online (SCIELO), Literatura Latino Americana e do Caribe em Ciências da Saúde (LILACS), Biblioteca Virtual de Saúde (BVS) e Google Acadêmico. Os critérios de inclusão publicados dentre o período estimado são estudos publicados entre 2012 até 2021 que constam nos idiomas português e inglês. Os critérios de exclusão foram artigos que não abordam as ideias coniventes do trabalho, artigos repetidos ou com insuficiência de dados e que não se enquadra no objetivo da pesquisa. Concluiu-se que a infecção oportunista de Cryptococcus neoformans apresentado acarretar o óbito de pacientes infectados pelo HIV. Nesses casos, o tratamento realizado em pacientes infectados pelo HIV com criptococose ocorre, inicialmente, adiando em até 5 semanas a terapia antirretroviral, após é iniciado a terapia antifúngica. Porém, no decorrer é necessário ter cuidado com o controle da pressão intracraniana para meningite criptocócica e o fornecimento de ARVs para restaurar a função imunológica são necessários para que o tratamento seja bem-sucedido. Por fim, destaca-se que é necessário investimento na saúde para que o diagnóstico precoce do fungo Cryptococcus neoformans seja feito de forma rápida e prestativa para este público, uma vez que este fungo é caracterizado como oportunista.
\end{abstract}

Palavras-chave: Cryptococcus neoformans; Diagnostico; Imunodeprimidos; Infecção oportunista; Tratamento.

\begin{abstract}
This research aims to understand the consequences of infection by Cryptococcus neoformans in patients with AIDS in Brazil, as well as to understand the development of $C$. neoformans in people with AIDS and highlight the diagnosis, symptoms and treatment of cryptococcosis. The present study consists of integrative bibliographic research with the main sources: articles, theses scientific journals electronic magazines. The digital platform seeks form: Scientific Electronic Library Online (SCIELO), Latin American and Caribbean Literature on Health Sciences (LILACS), Virtual Health Library (VHL) and Google Scholar. The inclusion criteria published within the estimated period are studies published between 2012 and 2021 that appear in the Portuguese english languages. Exclusion criteria were articles that do not address the conniving ideas of the work, repeated articles or with insufficient data and that does not fit the objective of the research. It was concluded that the opportunistic infection of $C$. neoformans presented result in the obtained of HIV-infected patients. In these cases, treatment in HIV-infected patients with cryptococcosis initially occurs, deporting antiretroviral therapy within 5 weeks, after antifungal therapy is initiated. However, in the course it is necessary to be careful with the control of intracranial pressure for cryptococcal meningitis and the supply of ARVs to restore immune function are necessary for the treatment to be successful. Finally, it is noteworthy that it is necessary to invest in health so that the early diagnosis of the fungus $C$. neoformans is made quickly and helpfully for this public, since this fungus is characterized as opportunistic.
\end{abstract}

Keywords: Cryptococcus neoformans; Diagnostics; Immunosuppressed; Opportunistic infection; Treatment. 


\begin{abstract}
Resumen
Esta investigación tiene como objetivo comprender las consecuencias de la infección por Cryptococcus neoformans en pacientes con sida en Brasil, así como comprender el desarrollo de C. neoformans en personas con sida y destacar el diagnóstico, síntomas y tratamiento de la criptococosis. El presente estudio consiste en una investigación bibliográfica integradora con las principales fuentes: artículos, tesis revistas científicas y revistas electrónicas. La plataforma digital busca la forma: Biblioteca Científica Electrónica Online (SCIELO), Literatura Latinoamericana y del Caribe en Ciencias de la Salud (LILACS), Biblioteca Virtual en Salud (BVS) y Google Scholar. Los criterios de inclusión publicados dentro del período estimado son estudios publicados entre 2012 y 2021 que aparecen en los idiomas inglés portugués. Los criterios de exclusión fueron artículos que no abordan las ideas conniventes del trabajo, artículos repetidos o con datos insuficientes y que no se ajustan al objetivo de la investigación. Se concluyó que la infección oportunista de $C$. neoformans presentó resultado en la obtención de pacientes infectados por VIH. En estos casos, el tratamiento en pacientes infectados por el VIH con criptococosis ocurre inicialmente, deportando la terapia antirretroviral dentro de las 5 semanas, después de que se inicia la terapia antimicótica. Sin embargo, en el curso es necesario tener cuidado con el control de la presión intracraneal para la meningitis criptocócica y el suministro de ARV para restaurar la función inmune son necesarios para que el tratamiento sea exitoso. Por último, cabe destacar que es necesario invertir en salud para que el diagnóstico precoz del hongo $C$. neoformans se realice de forma rápida y útil para este público, ya que este hongo se caracteriza por ser oportunista.
\end{abstract}

Palabras clave: Cryptococcus neoformans; Diagnóstico; Inmunodeprimido; Infección oportunista; Tratamiento.

\title{
1. Introdução
}

A criptococose $(\mathrm{Cr})$ é uma infecção fúngica respiratória predominantemente oportunista, causada pelo basidiomiceto do gênero Cryptococcus neoformans nas suas duas variedades: neoformans e gatti. A primeira ocorre mais frequentemente em indivíduos imunocomprometidos, disseminando-se por todo o organismo e apresentando alta mortalidade; a segunda, acomete principalmente indivíduos HIV negativos, sem fatores predisponentes para infecção fúngica. O C. neoformans var. pode ser adquirido no ambiente, pelo contato com solo contaminado com excretas de aves(principalmente pombos) e se distribui de forma cosmopolita , no o que diz respeito a $C$. gattii, os isolados são obtidos dos ocos de árvores e madeira em decomposição, primeiramente apontando as espécies de eucaliptos (Eucalyptus camaldulensis e E. tereticornis) de regiões de clima tropical e temperado como principal reservatório e, sendo observados em outras árvores nativas brasileiras como cássia, oiti, ficus e mulungu nas regiões norte e nordeste da Amazônia . Ele tem tropismo pelo Sistema Nervoso Central (SNC) e tem o HIV como principal fator predisponente para sua evolução. (Ferreira, 2016; Brito santos et al., 2015).

Observa-se que a criptococose assume caráter oportunista em pacientes vivendo com HIV-AIDS e imunossupressão avançada. A principal forma clínica, prevalecendo em $70 \%$ a $90 \%$ dos casos, é a meningoencefalite, responsável por 625.000 mortes anuais (Ferreira, 2016). A doença atinge primariamente os pulmões, podendo se manifestar na pele, ossos e gânglios linfáticos, sendo o principal agente causal dentro do complexo de espécies Cryptococcus neoformans, o C. neoformans var. grubii, responsável por 95\% dos casos da coinfecção Cr/HIV-AIDS (Gbangba-Ngai et al., 2014).

O HIV afeta principalmente o sistema imunológico, enfraquecendo os sistemas de defesa das pessoas contra infecções e alguns tipos de câncer. As PVHA se tornam gradualmente imunodeficientes, ficando assim mais suscetíveis a infecções que pessoas com um sistema imune saudável, visto que o vírus destrói as células de defesa do organismo e se replicam intensamente infectando novas células. A infecção pelo HIV é diferente da Aids. O estágio mais avançado da infecção por HIV pode demorar de dois a quinze anos para se manifestar, de acordo com cada indivíduo. A Aids é determinada pelo desenvolvimento de certos tipos de câncer, infecções ou outras manifestações clínicas graves (OPAS, 2017). Muitas mortes associadas ao HIV resultam de infecções que se beneficiam de um sistema imunológico enfraquecido do indivíduo. Isso inclui infecções bacterianas, como tuberculose, infecções virais como hepatite, infecções parasitárias como toxoplasmose e infecções por fungos, incluindo a histoplasmose (OPAS, 2020).

Segundo dados do Ministério da Saúde (MS) o Boletim Epidemiológico HIV/AIDS 2020, atualmente cerca de 920 mil pessoas vivem com HIV no Brasil, 89\% delas foram diagnosticadas, 77\% fazem tratamento com antirretrovirais até outubro do ano de 2020, cerca de 642mil pessoas estavam em tratamento com antirretroviral, enquanto que em 2018, eram 593.594 pessoas 
em tratamento Assim, o sistema imunológico do organismo humano está em constante batalha contra os antígenos, o Cryptococcus por estar amplamente distribuído no ar tona-se um patógeno em potencial para indivíduos imunodeprimidos, como pessoas HIV positivo (Moraes et al., 2018). Apesar dos avanços na área do tratamento da infecção pelo HIV com a terapia antirretroviral (TARV), que é altamente eficaz e segura, muitos pacientes ainda continuam a progredir para imunossupressão avançada associada ao quadro de HIV-AIDS (Almeida-Silva et al., 2016).

Antes da descoberta da terapia antirretroviral, as infecções fúngicas e outras infecções oportunistas eram um grande problema para as pessoas com HIV / AIDS em estágio avançado. Desde então, o número de infecções fúngicas e mortes devido a infecções fúngicas em pacientes avançados com HIV / AIDS diminuiu substancialmente em outros países desenvolvidos. A diminuição das infecções oportunistas deve-se principalmente ao diagnóstico precoce do HIV e ao início da terapia antirretroviral (ART), que evita que os pacientes com HIV atinjam o estágio em que seus sistemas imunológicos os expõem a infecções mais vulneráveis a fungos e outras. No entanto, doenças fúngicas, particularmente criptococose, ainda são uma preocupação para pacientes com HIV / AIDS (Bramantono, 2020). Assim, a questão norteadora do estudo é: quais as consequências da infecção por Cryptococcus neoformans em pacientes com AIDS no Brasil?

Devido a infecção por Cryptococcus neoformans ser um risco de vida ou morte aos pacientes com HIV / AIDS, estudar como ocorre a infecção, diagnósticos e tratamento da infecção fúngica torna-se primordial para destacar a importância da prevenção da doença oportunista. Além de oferecer a qualidade de vida das pacientes com HIV/AIDS e promovendo as informações necessárias para correta análise da evolução da doença e bem-estar da paciente, sendo esta justificativa do estudo realizado.

Diante disso o objetivo geral da pesquisa compreender as consequências da infecção por Cryptococcus neoformans em pacientes com AIDS no Brasil. Menciona-se que os objetivo específicos são: definir criptococose como uma infecção oportunista; compreender o desenvolvimento do neoformans em pessoas com AIDS; e elencar como ocorre o diagnóstico, quais são os sintomas, e a forma de tratamento da criptococose.

\section{Metodologia}

A metodologia é a aplicação de procedimentos e técnicas que devem ser observados para construção do conhecimento, com o propósito de comprovar sua validade e utilidade nos diversos âmbitos da sociedade (Prodanov, Freitas, 2013). Consistiu em uma pesquisa bibliográfica do tipo integrativa tendo como principais fontes: artigos, teses revistas cientificas revistas eletrônicas. A plataforma digital busca forma: Scientific Eletronic Library Online (SCIELO), Literatura Latino Americana e do Caribe em Ciências da Saúde (LILACS), Biblioteca Virtual de Saúde (BVS) e Google Acadêmico.

Os critérios de inclusão publicados dentre o período estimado são estudos publicados entre 2012 até 2021 que constam nos idiomas português e inglês. Os critérios de exclusão foram artigos que não abordam as ideias coniventes do trabalho, artigos repetidos ou com insuficiência de dados e que não se enquadra no objetivo da pesquisa. As palavras de busca foram: Cryptococcus neoformans; Diagnostics; Immunosuppressed; Opportunistic infection; Treatment. A Figura 1 apresenta o fluxograma a partir dos critérios de inclusão e exclusão. 
Figura 1. Fluxograma de critérios de exclusão e inclusão.

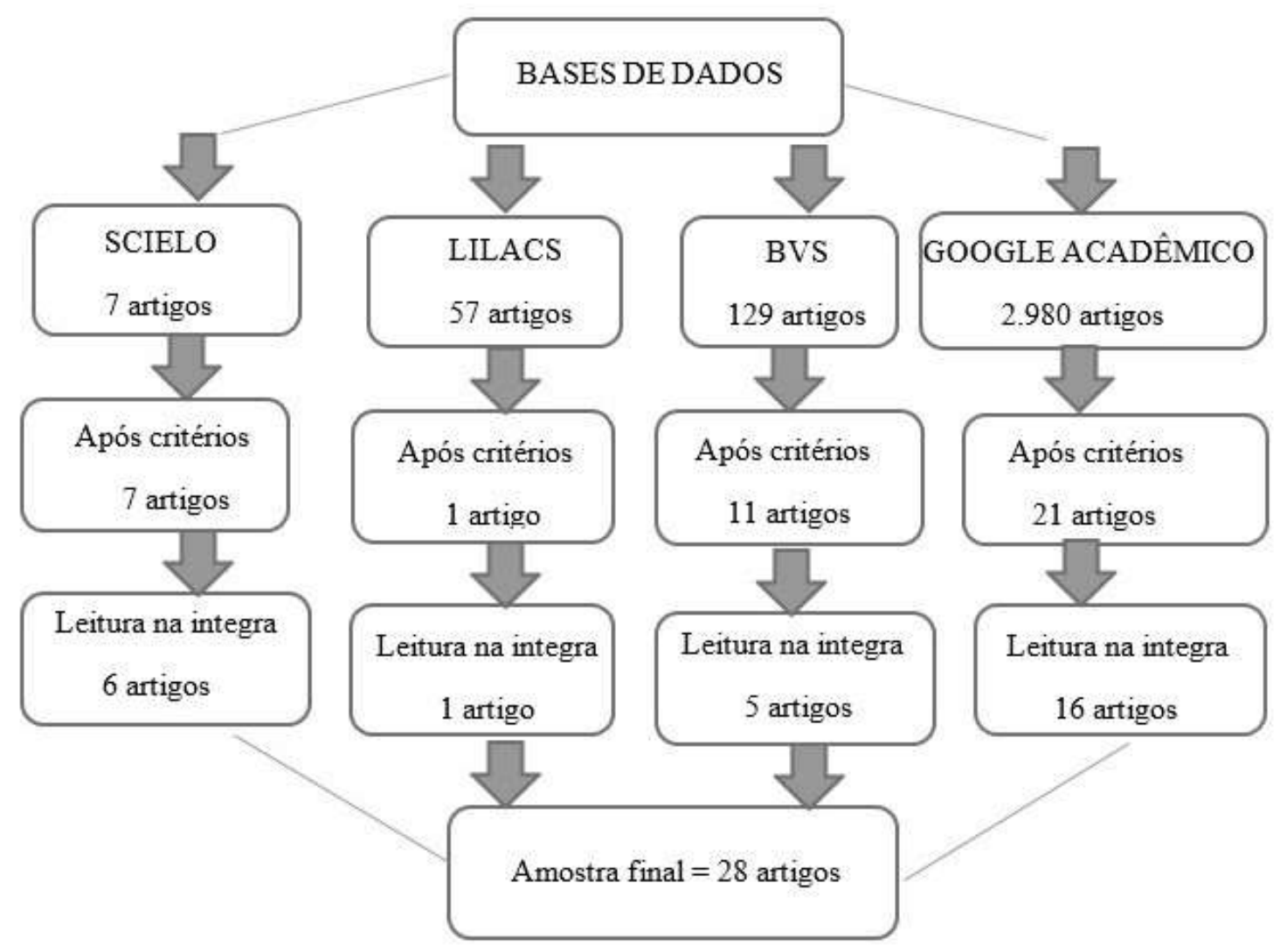

Fonte: Autores (2021)

\section{Resultados e Discussão}

Diante dos resultados encontrados após os critérios de exclusão e inclusão, desenvolveu-se um quadro com as características dos principais artigos selecionados, assim tabulou-se autor, ano de publicação, título, objetivo e principais resultados. Como descrito a seguir no Quadro 1.

Quadro 1. Quadro sinóptico de estudos selecionados.

\begin{tabular}{|c|c|c|c|}
\hline AUTOR/ANO & TÍTULO & OBJETIVO & PRINCIPAIS RESULTADOS \\
\hline Araújo, 2015 & $\begin{array}{l}\text { Cryptococcus: isolamento ambiental e } \\
\text { caracterização bioquímica. }\end{array}$ & $\begin{array}{c}\text { Pesquisar a existência de microfocos } \\
\text { de Cryptococcus sp. em amostras } \\
\text { ambientais. }\end{array}$ & $\begin{array}{c}\text { Resultados revelaram que } 17(34 \%) \text { dos } \\
\text { cultivos foram positivos para o } \\
\text { Gênero Cryptococcus, sendo nove (18\%) } \\
\text { para Cryptococcus gattii e oito (16\%) para } \\
\text { Cryptococcus neoformans. }\end{array}$ \\
\hline Carrijo, 2021 & $\begin{array}{l}\text { Análise clínicoepidemiológica de } \\
\text { criptococose em } \\
\text { indivíduos com HIV: uma revisão } \\
\text { sistemática. }\end{array}$ & $\begin{array}{l}\text { Objetivo estabelecer o perfil clínico- } \\
\text { epidemiológico e os fatores } \\
\text { determinantes da coinfecção entre a } \\
\text { criptococose e pessoas vivendo com } \\
\text { HIV. } \\
\end{array}$ & $\begin{array}{l}\text { Comprovada a importância do rastreio } \\
\text { precoce da criptococose e da MC em } \\
\text { pacientes com HIV, por meio de dosagens } \\
\text { rotineiras de crag ainda em pacientes sem } \\
\text { sintomas neurológicos. }\end{array}$ \\
\hline Derbie, 2018 & $\begin{array}{c}\text { Magnitude of Cryptococcal } \\
\text { Antigenemia among HIV } \\
\text { Infected Patients at a Referral Hospital, } \\
\text { Northwest Ethiopia. }\end{array}$ & $\begin{array}{c}\text { Analisar a infecção entre a } \\
\text { criptococose e pessoas vivendo com } \\
\text { HIV. }\end{array}$ & $\begin{array}{l}\text { Os resultados do estudo mostraram que esta } \\
\text { infecção fúngica oportunista é uma importante } \\
\text { preocupação de saúde entre os pacientes com } \\
\text { HIV. }\end{array}$ \\
\hline Diniz, 2019 & $\begin{array}{c}\text { Epidemiological and TNF } \alpha \\
\text { polymorphism evaluation in patients } \\
\text { with cryptococcal meningitis treated at } \\
\text { a referral hospital in North Brazil. }\end{array}$ & $\begin{array}{l}\text { Avaliar a epidemiologia da meningite } \\
\text { criptocócica e polimorfismos do gene } \\
\text { TNF } \alpha \text { em pacientes de um hospital de } \\
\text { referência no norte do Brasil. }\end{array}$ & $\begin{array}{l}\text { Cryptococcus neoformans era detectado } \\
\text { como o agente etiológico predominante } \\
(100 \%) \text { em pacientes HIV positivos. } \\
\text { Nenhuma mudança genética polimórfica foi } \\
\text { encontrada. }\end{array}$ \\
\hline Kwon-Chung 2017 & $\begin{array}{l}\text { Criptococose: padrões de mortalidade } \\
\text { no brasil e morbimortalidade em } \\
\text { hospital de referência do ceará. }\end{array}$ & $\begin{array}{l}\text { Objetivo caracterizar a mortalidade } \\
\text { relacionada à criptococose no Brasil e } \\
\text { os padrões de morbimortalidade da } \\
\text { doença em Hospital de Referência do } \\
\text { Ceará. } \\
\end{array}$ & $\begin{array}{l}\text { Mortalidade relacionada à criptococose no } \\
\text { Brasil apresenta tendência de declínio, o que } \\
\text { pode estar relacionado à melhor sobrevida e } \\
\text { qualidade de vida dos indivíduos com }\end{array}$ \\
\hline
\end{tabular}




\begin{tabular}{|c|c|c|c|}
\hline & & & $\begin{array}{l}\text { imunossupressão por HIV/Aids, } \\
\text { transplantados e outras condições. }\end{array}$ \\
\hline Luo, 2015 & $\begin{array}{l}\text { Clinical study of } 23 \text { pediatric patients } \\
\text { with cryptococcosis. }\end{array}$ & $\begin{array}{l}\text { Avaliar criptococcose em crianças } \\
\text { imunocompetentes. }\end{array}$ & $\begin{array}{l}\text { A criptococose ocorre em crianças não } \\
\text { infectadas pelo HIV e imunocompetentes. A } \\
\text { criptococose carece de manifestações } \\
\text { clínicas específicas. A criptococose } \\
\text { disseminada comumente ocorre em crianças. } \\
\text { Os médicos devem considerar um } \\
\text { diagnóstico de criptococose disseminada } \\
\text { para crianças que apresentam febre de longo } \\
\text { prazo inexplicada, tosse leve, exames de } \\
\text { imagem do tórax consistentes com os } \\
\text { sintomas clínicos, linfadenectasia, } \\
\text { hepatoesplenomegalia e eosinofilia. }\end{array}$ \\
\hline Molloy, 2018 & $\begin{array}{l}\text { Antifungal combinations for treatment } \\
\text { of cryptococcal meningitis in Africa. }\end{array}$ & $\begin{array}{c}\text { Analisar as formas de tratamentos e } \\
\text { as drogas utilizadas. }\end{array}$ & $\begin{array}{l}\text { Os resultados demostram que uma semana } \\
\text { de anfotericina B mais flucitosina e } 2 \\
\text { semanas de fluconazol mais flucitosina } \\
\text { foram eficazes como terapia de indução para } \\
\text { meningite criptocócica em ambientes com } \\
\text { recursos limitados. } \\
\end{array}$ \\
\hline Moraes, 2018 & $\begin{array}{l}\text { Fisiopatologia da criptococose em } \\
\text { pacientes com HIV/AIDS e o papel do } \\
\text { biomédico. }\end{array}$ & $\begin{array}{c}\text { Explanar sobre a infecção fúngica } \\
\text { causada pelo Cryptococcus } \\
\text { neoformans em pacientes com } \\
\text { síndrome da imunodeficiência } \\
\text { adquirida. }\end{array}$ & $\begin{array}{l}\text { As infecções em pacientes } \\
\text { imunocomprometidos são a segunda maior } \\
\text { causa de óbitos, chamando a atenção das } \\
\text { autoridades públicas para programas de } \\
\text { prevenção, diagnóstico e tratamentos. }\end{array}$ \\
\hline Oliveira, 2020 & $\begin{array}{l}\text { Criptococcose: causas, tratamento e } \\
\text { epidemiologia. }\end{array}$ & $\begin{array}{l}\text { Levantar os principais pontos sobre a } \\
\text { doença e seus agentes etiológicos. }\end{array}$ & $\begin{array}{l}\text { Resultados demonstram que é necessário } \\
\text { estudos elucidativos acerca da } \\
\text { patogenicidade do fungo, além de } \\
\text { estratégias de conscientização sobre a } \\
\text { prevenção do HIV. }\end{array}$ \\
\hline Queiroz, 2018 & $\begin{array}{l}\text { Relação entre a criptococose e } \\
\text { indivíduos portadores do HIV. }\end{array}$ & $\begin{array}{l}\text { Identificar na literatura científica a } \\
\text { relação entre a criptococose causada } \\
\text { pelo Cryptococcus neoformans var. } \\
\text { neoformans e AIDS. }\end{array}$ & $\begin{array}{l}\text { Possibilitar um diagnóstico precoce e um } \\
\text { melhor prognóstico para esses doentes, } \\
\text { traduzindo-se assim numa melhoria marcada } \\
\text { da sobrevida, que é de apenas } 20-30 \% \text { em } \\
\text { doentes não tratados. }\end{array}$ \\
\hline Souza, 2018 & $\begin{array}{l}\text { Incidência de Cryptococcus } \\
\text { neoformans em fezes de pombos } \\
\text { (Columba Livia) na área central da } \\
\text { cidade de Porto Velho, RO. }\end{array}$ & $\begin{array}{c}\text { Avaliar a incidência de C. } \\
\text { Neoformans em fezes de pombos na } \\
\text { área central do município de Porto } \\
\text { Velho. }\end{array}$ & $\begin{array}{l}\text { Resultados evidenciaram um percentual de } \\
30 \% \text { dos locais com presença de excretas e } \\
\text { que essas amostras foram confirmadas } \\
\text { contendo C. Neoformans. }\end{array}$ \\
\hline Silva, 2018 & $\begin{array}{l}\text { Criptococose em um centro de } \\
\text { referência em HIV-AIDS no extremo } \\
\text { sul do brasil. }\end{array}$ & $\begin{array}{c}\text { Traçar o perfil clínico, } \\
\text { epidemiológico da criptococose em } \\
\text { pacientes HIV/AIDS atendidos no } \\
\text { serviço de referência do HUFURG. }\end{array}$ & $\begin{array}{l}\text { Estudo evidenciou } 70 \text { casos de neoformans, } \\
\text { em que o cultivo foi }(\mathrm{n}=44) 74,3 \% \text { sexo } \\
\text { masculino, idade ( } 20 \text { e } 78 \text { anos) } 84,3 \% \\
\text { apresentação clínica de Neurocriptococose. }\end{array}$ \\
\hline Vidal, 2018 & $\begin{array}{l}\text { Desempenho do ensaio de fluxo lateral } \\
\text { do antígeno criptocócico no soro, } \\
\text { líquido cefalorraquiano, sangue total e } \\
\text { urina em pacientes infectados pelo } \\
\text { HIV com meningite criptocócica } \\
\text { comprovada por cultura admitidos em } \\
\text { um centro de referência brasileiro. }\end{array}$ & $\begin{array}{c}\text { Estabelecer o perfil clínico- } \\
\text { epidemiológico e os fatores } \\
\text { determinantes da coinfecção entre a } \\
\text { criptococose e pessoas vivendo com } \\
\text { HIV. }\end{array}$ & $\begin{array}{l}\text { Trata-se de um estudo caso controle } \\
\text { prospectivo, com } 20 \text { pacientes infectados } \\
\text { pelo HIV com primeiro episódio de } \\
\text { meningite criptocócica e } 33 \text { pacientes } \\
\text { infectados pelo HIV no grupo controle. } \\
\text { Realizado no Instituto de Infectologia } \\
\text { Emílio Ribas/SP. Em conclusão, CrAg LFA } \\
\text { no soro, LCR e sangue total mostrou alta } \\
\text { sensibilidade e especificidade. CrAg LFA de } \\
\text { sangue total parece ser uma estratégia boa e } \\
\text { confiável para melhorar o diagnóstico de } \\
\text { meningite criptocócica relacionada à AIDS } \\
\text { no Brasil. }\end{array}$ \\
\hline
\end{tabular}

Fonte: Autores (2021).

\subsection{Criptococose no Brasil}

A criptococose é uma doença de distribuição e impacto mundial. A partir da década de 1980 com a epidemia aids, os estudos sobre a doença tornaram - se mais evidentes, pois a criptococose se tornou uma doença oportunista com considerável impacto nas taxas de morbidade e mortalidade. A doença é cosmopolita, causada por leveduras do gênero Cryptococcus. As espécies desse gênero são encapsuladas, e foram descritas pela primeira vez no fim do século XIX. Taxonomicamente, pertencem a classe Tremellomycetes, família Tremellaceae e gênero Cryptococcus, pode ser capaz de infectar uma ampla gama de seres vivos, como por exemplo, humanos e animais (Oliveira, 2018). 
No Brasil a tendência epidemiológica macrorregional, norte e sul, para as infecções por C. neoformans e C. gatti na macrorregião norte, composta pelos estados do Amazonas, Roraima, Pernambuco, Piauí e Bahia, o tipo molecular VGII prevalece em hospedeiros imunocompetentes, e a micose se comporta como endemia regional. Na macrorregião Sul composta pelos estados de Mato Grosso do Sul, Minas gerais, São Paulo, Rio de Janeiro, Paraná e Rio Grande do Sul, o tipo molecular VNI é mais prevalente em hospedeiros imunocomprometidos, ou seja, aqueles que portadores de Aids (Oliveira, 2018).

Os fungos Cryptococcus neoformans existentes no Brasil, levanta-se grande alerta para tomadas de medidas prevenção de toda população em destaque para imunodeprimidos. Pois a criptococcose é uma doença causada por duas espécies: $C$. neoformans e $C$. gattii. O fungo $C$. neoformans é comumente reportada em pessoas portadoras de HIV/AIDS ou com imunodepressão, enquanto a doença por $C$. gattii atinge principalmente pessoas imunocompetentes (Oliveira, 2020).

Após diferentes estudos de análise de sequências de DNA, ecologia, epidemiologia e patologia, a atual classificação foi modificada, demonstrando que não se trata de duas variedades, mas sim de duas espécies distintas: C. neoformans, que abrange var. grubii (serotipo A) e var. neoformans (serotipo D), e C. gattii (serotipos B e C), conforme demonstrado no quadro 2 (KwonChung et al., 2015). Os cinco serotipos são ainda divididos em oito diferentes tipos moleculares: VNI/VNII (var. grubii, serotipo A), VNIII (serotipo AD), VNIV (var. neoformans, serotipo D), VGI, VGII, VGIII e VGIV (var. gattii, serotipo B e C) (Srikanta; Santiago-Tirado; Doering, 2014). O Quadro 2 apresenta a atual classificação das espécies de Cryptococcus.

Quadro 2. Atual classificação das espécies de Cryptococcus.

\begin{tabular}{|c|c|c|c|}
\hline \multicolumn{3}{|c|}{ Variedades, serotipagens e tipos moleculares das espécies de Cryptococcus } \\
\hline Espécie & Variedade & Sorotipo & Tipo molecular \\
\hline \multirow{2}{*}{ C. neoformans } & & & VNI/VNII \\
& & A & VNIV \\
\cline { 1 - 2 } C. gattii & var. grubbi & D & VNIII \\
& var. neoformans N.A. & AD & VGI \\
& & B e C & VGII \\
& & & VGIII \\
& & & VGIV \\
\hline
\end{tabular}

Fonte: Adaptado de Oliveira (2020).

Estudos de Araújo et al. (2017), apontam que o Cryptococcus neoformans é uma levedura capsulada, e o agente causador da criptococose, infecção grave que afeta principalmente pacientes imunocomprometidos. Esse fungo caracteriza-se como cosmopolita, pois está presente no meio ambiente, em plantas e animais, além disso, pode ser encontrado em diferentes nichos das áreas ambientais.

Souza, Sousa e Derbie (2018) o Cryptococcus neoformans, um agente causador da criptococose, é considerado um importante fator etiopatogênico de morbimortalidade infecciosa, especialmente entre pacientes HIV positivos Dessa forma a importância de saber que existem duas espécies de Cryptococcus, e que não somente está associada a indivíduos com imunodeprimidos, como também em pessoas saudáveis.

\subsection{Infecção Oportunista}

Diniz (2019) descreve a criptococcose é uma infecção fúngica oportunista que atinge principalmente pulmões e sistema nervoso central. Considerada uma das mais devastadoras infecções fúngicas humanas (Silva, 2018), a criptococcose é causada por duas espécies de leveduras encapsuladas do gênero Cryptococcus, Cryptococcus neoformans (C. neoformans) e 
Cryptococcus gattii (C. gattii), as quais são adquiridas no ambiente (Kwon-Chung et al., 2015). A criptococcose causada por $C$. neoformans afeta predominantemente pacientes imunocomprometidos, sendo reportada como a micose oportunista mais comum em portadores de HIV-AIDS, enquanto a criptococcose por C. gattii são mais frequentemente relatadas em indivíduos saudáveis (Firacative et al., 2018).

A infecção por Cryptococcus ocorre usualmente por inalação de um esporo ou levedura dessecada, que pode então se disseminar do pulmão até o cérebro ou para outros tecidos. A criptococcose afeta, principalmente, o pulmão que é o local de início da doença, além do sistema nervoso central causando meningite e encefalite e, em menor proporção, afeta outros órgãos como pele, olhos, próstata e ossos (Firacative et al., 2018). A meningite criptocócica é uma infecção oportunista com alta taxa de mortalidade e morbidade, cujos sobreviventes podem sofrer de cegueira irreversível e surdez, além de deficiências neurocognitivas (Kwon-Chung et al., 2015).

Os pacientes com criptococose podem ser assintomáticos. Todos os pacientes com infecção por HIV que apresentam cefaleia subaguda ou crônica, particularmente aqueles com depleção de CD4, devem ser investigados para MC. A punção lombar deve ser realizada para medir a pressão de abertura, contagem de células no líquido cefalorraquidiano (LCR), cultura bioquímica, CrAg no LCR, coloração de Gram e tinta da Índia, juntamente com soro CrAg, hemocultura e radiografia de tórax (Chastain, Henao-martínez, Franco-paredes, 2017).

\subsection{Desenvolvimento do neoformans em pessoas com AIDS}

O Vírus da Imunodeficiência Humana (HIV) é um retrovírus com tropismo por linfócitos T que possuem marcadores CD4+, esse vírus possui um ciclo lisogênico que ocorre na fase assintomática/latência clínica, ou seja, as funções da célula não são alteradas durante esse período, contudo, a presença de sintomas aparecerá quando o ciclo lisogênico torna-se lítico, e os vírus são liberados na corrente sanguínea infectando outras células CD4+, e devido ao rompimento da célula hospedeira os números de linfócitos TCD4+ diminuem drasticamente, comprometendo a defesa do organismo contra patógenos oportunistas (Moraes et al., 2018).

O Cryptococcus não é expelido pelo epitélio respiratório, pode invadir os alvéolos, onde será confrontado pelos macrófagos alveolares. A interação entre a levedura e os macrófagos alveolares é de suma importância para determinar a evolução da doença, pois caso os macrófagos não consigam eliminar o Cryptococcus, este pode alcançar a corrente sanguínea e se disseminar para outros locais, como pele, olhos, próstata e sistema nervoso central - pelo qual possui tropismo. (Moraes, Rodrigues et al., 2018).

Além do trato respiratório, inoculação direta no tecido através de trauma ou transplante de tecido infectado também podem ser consideradas portas de entradas ocasionais. Embora a criptococose pulmonar seja menos comum que a meningite ela é bem descrita na literatura, e quase todos os pacientes com AIDS apresentam sintomas, como febre (81\%), tosse (63\%), dispnéia (50\%), perda de peso (47\%), dor de cabeça (41\%), dor torácica pleurítica e hemoptise (Moraes et al., 2018).

\subsection{Diagnóstico}

O diagnóstico da infecção por Cryptococcus pode ser feita a partir de amostras de líquor, sangue, medula óssea, tecidos, secreções (trato respiratório, nasal, oral, nasofaringe), pus e aspirados (subcutâneo, ganglionar, cerebral, pulmonar, mucosa e outros). A técnica mais utilizada é o exame microscópico direto com coloração, é uma técnica rápida e barata, na qual é possível visualizar a levedura cercada por um espesso halo transparente, que caracteriza sua cápsula polissacarídica, sobre o fundo preto produzido pelo corante. O diagnóstico da criptococose é clínico e laboratorial. A confirmação laboratorial é feita com o uso de "tinta da China" (tinta nanquim), com evidências de criptococos visíveis em materiais clínicos (Moraes Rodrigues et al., 2018). 
Figura 2. Cryptococcus neoformans em exame direto de líquor, preparado com tinta nanquim. (400X).

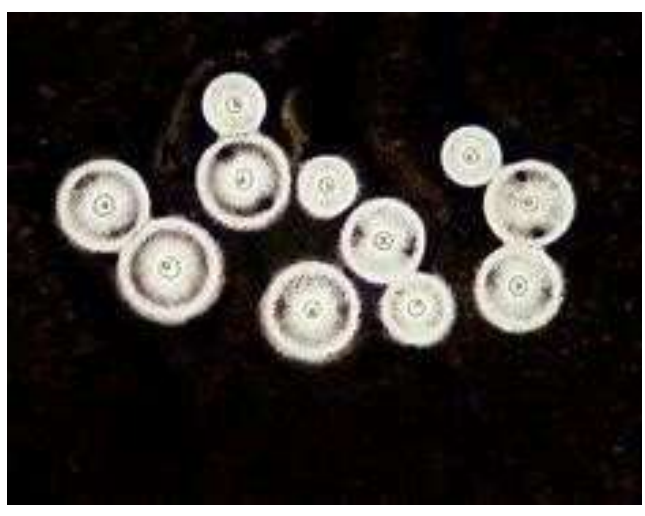

Fonte: Oliveira (2017).

Oliveira (2018) aponta que em meio de cultivo, o agente possui um crescimento rápido de 3 a 7 dias com temperatura entre $25^{\circ}$ e $37^{\circ} \mathrm{C}$, desde que não contenha cicloheximida, antifúngico que inibe o crescimento do Cryptococcus, sua colônia mucóide apresenta coloração de branco-creme ao amarelo-marrom.3;17;20;26 Também é possível o cultivo em meio CGB (canavanina, glicina e azul-de-bromotimol), que permite a identificação dos dois sorogrupos. O Sorogrupo B/C, por utilizar glicina como substrato, esse sorogrupo consegue se desenvolver no meio com canavanina tornam o meio azul-cobalto, enquanto o sorogrupo A/D não possui nenhum crescimento nesse meio, mantendo sua coloração inalterada.17;26. Em cortes histológicos é factível a coloração por meio das seguintes técnicas: método de Grocott, constituído por impregnação pela prata, que cora de negro a parede celular da levedura, permitindo sua visualização sobre um fundo verdeclaro. Método Mucicarmim de Mayer, que evidencia a cápsula do Cryptococcus com coloração avermelhada. (Hagen, 2017).

\subsection{Sintomas e tratamento}

C. neoformans acomete principalmente pulmão e/ou sistema nervoso central, podendo ainda envolver pele, próstata e olhos, ou ter apresentação em vários órgãos, com disseminação. Nos pacientes imunocompetentes, cerca de um terço dos casos são assintomáticos, apenas com achados radiológicos ao acaso. Os pacientes sintomáticos podem apresentar evidência de quadro infeccioso como febre, tosse, dor torácica, perda de peso e escarro purulento (Henao-Martinez \& Beckham, 2015).

Estudos feitos por Ramírez et al. (2017) demonstram que apesar do acesso à TARV estar diretamente relacionado ao melhor o prognóstico de pacientes infectados pelo HIV, a cobertura do tratamento permanece relativamente baixa e o diagnóstico da infecção pelo HIV ainda é tardio. Como resultado, muitos pacientes evoluem a óbito em decorrência de infecções oportunistas (IOs) relacionadas ao HIV nas semanas anteriores e meses após o início da TARV.

Kwon-Chung et al. (2015) aponta que desde os anos de 1960, a Anfotericina B é considerada o medicamento padrão ouro no tratamento da criptococcose. A Anfotericina B (AMB) ou o Fluconazol associados ou não ao 5- Flucitosina (5FC) são a base do tratamento. Estudos de Molloy et al., 2018, mostraram resultados satisfatórios como uma semana de anfotericina B associado a flucitosina e 2 semanas de fluconazol mais flucitosina.

Vidal et al. (2018) demonstraram em seu estudo certo benefício (menor risco de morte) nos pacientes com HIV e infecção criptocócica assintomática que iniciaram o tratamento com TARV e fluconazol quando comparados com estudos em que os pacientes não foram tratados, corroborando para o contexto da necessidade de prevenção da MCO Cryptococcus neoformans corresponde ao estado mitospórico do basidiomiceto Filobasidiella neoformans, sua fase sexuada. Dentre os principais fatores de virulência do Cryptococcus estão: síntese de cápsula polissacarídica, ergosterol, fosfolipase, urease, melanina, proteinase, e crescimento em temperatura de $37^{\circ} \mathrm{C}$ (Moraes et al., 2018). 
Dessa forma, é comprovada a importância do rastreio precoce da criptococose e da meningite criptocócica em pacientes com HIV, por meio de dosagens rotineiras de CrAg ainda em pacientes sem sintomas neurológicos, a fim de introduzir precocemente a terapia antifúngica e reduzir a morbimortalidade desses pacientes. Essa revisão deverá servir de alerta à comunidade científica em relação aos preditores de mortalidade, no sentido de priorizar a prevenção da consequências da infecção por Cryptococcus em pacientes com HIV, por meio do amplo acesso a TARV, bem como servir de base para incitar a incorporação da dosagem do CrAg à rotina ambulatorial e hospitalar no atendimento aos pacientes infectados pelo HIV, fomentando a melhora dos dados epidemiológicos atuais (Sharma et al., 2017).

\section{Considerações Finais}

A partir da pesquisa realizada, observou-se que o desenvolvimento da doença criptococose no Brasil leva uma população de risco a consequências estarrecedoras, pois estima-se que atualmente, cerca de 920 mil pessoas vivem com HIV no Brasil, de acordo com o Ministério da Saúde.

A partir dos achados verificou-se que a infecção oportunista de Cryptococcus neoformans acarreta o óbito de pacientes infectados pelo HIV. Nesses casos, o tratamento realizado em pacientes infectados pelo HIV com criptococose ocorre, inicialmente, adiando em até 5 semanas a terapia antirretroviral, após é iniciado a terapia antifúngica. Porém, no decorrer é necessário ter cuidado com o controle da pressão intracraniana para meningite criptocócica e o fornecimento de ARVs para restaurar a função imunológica são pontos necessários para que o tratamento seja bem-sucedido.

Destaca-se também que é necessário investimento na saúde para que o diagnóstico precoce do fungo Cryptococcus neoformans e que este seja feito de forma rápida e prestativa para este público, uma vez que este fungo é caracterizado como oportunista. Além de ser importante enfatizar a necessidade de pesquisas dentro dessa área para maiores contribuições na clínica, diagnóstico e terapêutica de doença.

\section{Referências}

Almeida-Silva, F. et al. (2016) Multiple opportunistic fungal infections in an individual with severe HIV disease: a case report. Revista iberoamericana de micologia, 33(2), 118-121.

Araújo Júnior, E. C. A., Táparo, C. V., Uchida, C. Y., \& Marinho, M. (2015). Cryptococcus: isolamento ambiental e caracterização bioquímica. Arquivo Brasileiro de Medicina veterinária e zootecnia, 67(4), 1003-1008.

Brito-Santos F., Barbosa G. G., Trilles L., Nishikawa M. M., Bodo Wanke B., Meyer W., Carvalho-Costa F. A., \& Lazéra M. S. (2015) Environmental Isolation of Cryptococcus gattii VGII from Indoor Dust from Typical Woen Houses in the Deep Amazonas of the Rio Negro Basin. PLoS ONE. 10(2),0115866.

Carrijo, A. V., Carrijo, B. V., Machado, L. N., Almeida, R. J de, \& Oliveira, P. P. C. de. (2021). Análise clínico-epidemiológica de criptococose em indivíduos com hiv: uma revisão sistemática/clinical-epidemiological analysis of cryptococosis and hiv coinfection. Brazilian Applied Science Review, 5 (2), 802-817.

Chastain, D. B., Henao-martínez, A. F., \& Franco-paredes, C. (2017) Opportunistic invasive mycoses in Aids: cryptococcosis, histoplasmosis, coccidiodomycosis, and talaromycosis. Current infectious disease reports, 19(10), 36.

Derbie, A. et al. (2018) Magnitude of Cryptococcal Antigenemia among HIV Infected Patients at a Referral Hospital, Northwest Ethiopia. Ethiopian Journal of Health Sciences, 28(4).

Diniz, A. M. M., Feio, D. C. A., Silva, A. S. N., Burbano. R. R., \& Lima, P. D. L de. (2019). Epidemiological and TNFa polymorphism evaluation in patients with cryptococcal meningitis treated at a referral hospital in North Brazil. Rev. Soc. Bras. Med. Trop. (52).

Ferreira, M. D. F. (2016). Prevalência de antigenemia criptocócica em pacientes HIV positivos com imunossupressão avançada no Instituto Nacional de Infectologia Evandro Chagas (Doctoral dissertation).

Firacative C., Lizarazo J., Illnait-ZaragozÍ M. T., \& Castañeda E. (2018) The status of cryptococcosis in Latin America. Mem. Inst. Oswaldo Cruz. 113(7), e170554.

Gbangba-Ngai E., Fikouma V., Mossoro-Kpinde C. D., Tekpa G., Ouavene J. O., Yangba Mongba D. S. A., \& Mbelesso P. (2014) La cryptococcose neuroméningée au cours de l'infection à VIH à Bangui, à l'ère du traitement antirretroviral. Bull. Soc. Pathol. Exot. 107, 106-109.

Henao-Martínez A. F., \& Beckham J. D. (2015) Cryptococcosis in solid organ transplant recipientes. Curr Opin Infect Dis. 28(4), 
HAgen F, et al. (2017) Importance of Resolving Fungal Nomenclature: the Case of Multiple Pathogenic Species in the Cryptococcus Genus. MSphere.2(4): e 00238-17.

Kwon-Chung, K. J., et al. (2017) The Case for Adopting the "Species Complex" Nomenclature for the Etiologic Agents of Cryptococcosis. mSphere. 2(1),27e00357-16.

Luo, F. L. et al. (2015) Clinical study of 23 pediatric patients with cryptococcosis. Eur Rev Med Pharmacol Sci, 19(20), 38013810.

Molloy, S. F. (2018) et al. Antifungal combinations for treatment of cryptococcal meningitis in Africa. New England Journal of medicine. 378(11), 1004-1017.

Moraes, G. Y. B. de, et al (2018) Invencioni, Fisiopatologia Da Criptococose Em Pacientes Com Hiv/Aids E O Papel Do Biomédico Physiopathology Of Cryptococosis In Patients With Hiv / Aids And The Role Of Biomedical. Ed - n 10.

Oliveira, L. V. V. D. (2020). Criptococcose: causas, tratamento e epidemiologia.

Oliveira, L. D. Q. (2017). Influência dos óleos essenciais de cinnamomum cassia e cymbopogon flexuosus sobre a suscetibilidade e fatores de virulência em leveduras do complexo Cryptococcus neoformans. (Dissertação de Mestrado). Universidade Federal de Goiás, Goiânia.

Organização Pan-Americana da Saúde (OPAS). Acesso a medicamentos para HIV foi severamente impactado pela COVID-19. OPAS/MS, 2020 https://www.paho.org/pt/noticias/6-7-2020-oms-acesso-medicamentos-para-hiv-foi-severamente-impactado-pela-covid-19.

Organização Pan-Americana da Saúde (OPAS). Doenças Transmissíveis \& Análise de Situação de Saúde: OPAS/MS, 2017. https://www.paho.org/bra/index.php?option=com_content\&view=article\&id=5666:folha-informativa-hiv-aids\&Itemid=812.

Prodanov., C. C., \& De Freitas., E. C, (2013). Metodologia do Trabalho Científico: Métodos e Técnicas da Pesquisa e do Trabalho Acadêmico.

Queiroz, E. P., Santana, J. C., Barbosa, L. M. S., \& Maia, C. S. (2018). Relação entre a criptococose e indivíduos portadores do HIV. American Journal of HIV/AIDS Research.

Silva., L. B. (2018) Criptococose em um centro de referência em HIV-AIDS no Extremo Sul do Brasil,p 77.

Souza, R. G. de, \& Souza, C. M. de. (2018). Incidência de Cryptococcus neoformansem fezes de pombos (Columba Livia) na área central da cidade de Porto Velho, RO. Revista Saber Cientifico, 7(1), 13-22.

Srikanta D., Santiago- Tirado F. H., \& Doering, T. L. (2014) Cryptococcus neoformans: historical curiosity to modern pathogen Yeast. 31(2), 47-60.

Sharma, S. R. et al. (2017) Neurological manifestations of HIV-AIDS at a tertiary care institute in North Eastern India. Neurology India. 65, (1) 64. DOI: $10.34115 /$ basrv5n2-014

Vidal, J. E. et al. (2018) Performance of cryptococcal antigen lateral flow assay in serum, cerebrospinal fluid, whole blood, and urine in HIV-infected patients with culture-proven cryptococcal meningitis admitted at a Brazilian referral center. Revista do Instituto de Medicina Tropical de São Paulo. 5(2),60. 